\title{
Подготовка селекционеров в вузах и исполнение федеральных селекционных программ в России
}

\section{В.Е. Бердышев, Н.Н. Клименко, В.И. Леунов, В.В. Пыльнев}

Представлены краткие данные о подготовке кадров ученых-селекционеров за рубежом, подробная информация о системе обучения селекционеров в Российской Федерации, затронуты основные проблемы отечественного образования в сфере селекции с.- х. культур в связи с государственными селекционными программами.

Ключевые слова: подготовка кадров, селекция, семеноводство

елекция зерновых культур, картофеля и овощей во всем мире ведется государственными и частными компаниями и по факту является отраслевой наукой. О ее уровне судят по посевным площадям, занятыми конкретными селекционными разработками. В России сегодня большинство площадей полевых культур (за исключением гибридов подсолнечника, свеклы сахарной, кукурузы, сортов рапса и картофеля) занимают отечественные сорта и гибриды. В то же время большую часть площадей под овощными культурами занимают сорта и гибриды зарубежной селекции, что позволяет говорить о высоком уровне зарубежных селекционных разработок.

Именно селекция позволяет государственным институтам и частным компаниям занимать ведущие места на рынке, поскольку обладание уникальными сортами и гибридами дает им возможность быть более конкурентоспособными. Лидерство в конечном счете определяется конкретными сортами или гибридами, которые создают селекционеры. Причем важно отметить, что высококлассный селекционер, как правило, работает с одной культурой или несколькими родственными культурами, и это не просто «Профи», а это еще и «Художник». Стать селекционером «от Бога» позволяют врожденный талант и серьезная профессиональная подготовка. Поэтому селекционеров с мировым именем не так уж много. Ведущие отечественные селекционеры широко известны. А вот у иностранных компаний селекционеры часто попадают в категорию «ноу хау», и их имена и деятельность особенно не афишируются.
Важно разобраться, а откуда же берутся селекционеры, которые могут создавать уникальные, высококонкурентные селекционные разработки. В советское время была отстроена достаточно эффективная система подготовки селекционеров, которая логично вписывалась в плановую экономику. Сегодня на дворе рынок. Причем не просто рынок - в Россию пришел жесткий мировой рынок лучших селекционных разработок. И создают их естественно селекционеры. Глядя на отечественный и зарубежный опыт, можно сказать, что селекционер - это продукт теоретической и научной подготовки университетов и практической подготовки государственных или частных селекционно-семеноводческих компаний. В государственных институтах и частных компаниях сосредоточен уникальный селекционный материал по различным культурам, из которого можно создать конкурентный сорт или гибрид. А если с этим материалом работают селекционеры-профессионалы, успех гарантирован. А вот готовить селекционеров-профессионалов зарубежные компании часто начинают еще с обучения в вузах. У серьезных селекционных компаний отстроены тесные связи с университетами, готовящими соответствующих специалистов. Со студенческой скамьи идет теоретическое погружение в круг вопросов, связанных с той или иной с.х. культурой и практическое познание материала компании. Студенты вовлечены в реальный научный процесс, результаты которого нужны компании, а компания таким образом готовит и подбирает для себя соответствующих специалистов. Кстати, таким же образом идет подготовка и других специалистов, задействованных в селекционном процессе: биотехнологов, специалистов по иммунитету и т.д. При этом для подготовки специалистов активно используется материально-техническая научная база институтов и компаний, а также система повышения квалификации в различных научных центрах и организациях.

В современном растениеводстве (включая полевые, овощные, плодово-ягодные, декоративные и даже некоторые лесные культуры) возделывают сорта и гибриды - продукты отрасли с. - х. производства, именуемой селекцией. Они призваны обеспечивать высокую урожайность и качество продукции.

По разным источникам, селекция обеспечивает сегодня от 25 до 40\% роста урожайности. Остальное приходится на долю технологии возделывания. Есть примеры и более значительного вклада селекции в рост урожайности. Так, создание короткостебельных сортов яровой пшеницы позволило увеличить урожайность этой культуры в Мексике в три раза, а в некоторых штатах этой страны - в семь раз. Селекции доступны также такие изменения качества продукции, которые не под силу агротехнике, например, изменение цветовой гаммы цветов декоративных культур, состава масла у масличных культур, значительное улучшение хлебопекарных качеств муки у пшеницы, увеличение содержания ценных лекарственных веществ у лекарственных растений и т.д. Прогнозируется дальнейшее увеличение роли селекции в росте урожайности и совершенствовании качества продукции возделываемых культур.

Заметна и средообразуюшая роль селекции. Речь идет о накоплении в почве доступных форм азота бобовыми культурами, поглощении радионуклидов из почвы после ее радиоактивного загрязнения, дренирующего действия некоторых древесных растений и т.д. Словом, все свойства наследственного характе- 
ра могут быть изменены селекцией на пользу человека.

Значение квалифицированного специалиста-селекционера для успешного развития отрасли трудно переоценить. Такой специалист должен хорошо знать технологию селекционного процесса, т.е. процесса создания сорта или гибрида. При этом он должен знать не только техническую сторону селекционного процесса, но и его научное обоснование, быть способным выбрать наиболее эффективную селекционную технологию.

Особое значение имеет также работа агрономов-семеноводов, обеспечивающих размножение и внедрение в производство сортов и гибридов, созданных селекционерами

Потребность в специалистах-селекционерах в стране крайне велика. Кадры селекционеров катастрофически стареют, необходимо вовремя готовить им замену, чтобы действующие селекционеры могли передать свой опыт и наработанный селекционный материал молодежи. Для действующих в стране 46 селекционных центров, НИИ, селекционно-семеноводческих фирм в год требуется 50-60 выпускников ВУЗов. И если будущего семеновода можно подготовить в процессе обучения студента по направлению «Агрономия», или доучить его в магистратуре, то подготовка научного работника-селекционера более специфична. Она невозможна без знания им ряда фундаментальных и прикладных дисциплин: генетики, ботаники, физиологии растений экологии, фитопатологии, энтомологии, основ с.- х. опытного дела, растениеводства, земледелия и ряда других. Т.е. научный работник-селекционер изначально должен иметь хорошую общебиологическую и агрономическую подготовку, на которую накладывается специфические знания в области селекции, генетики, биотехнологии.

В Советском Союзе и в Российской Федерации осуществлялась целенаправленная подготовка селекционеров, не имеющая аналогов в мире. В разное время в стране селекционеров готовили в рамках отдельной специальности или специализации "Селекция и семеноводства» в рамках подготовки ученого-агронома.

C 1988 года по инициативе Московской с.- х. академии имени К.А.Тимирязева (ТСХА) была открыта отдельная специальность «Селекция и генетика с.- х. растений», а в 1993 году был проведен первый выпуск специалистов-селекци- онеров. В стране имелось одиннадцать ВУЗов, осуществлявших подготовку по этой специальности. По стране ее курировала кафедра генетики, селекции и семеноводства полевых культур ТСХА.

Эта специальность отличается от других агрономических специальностей большей наукоемкостью, что нашло отражение в программах и учебных планах, подготовленных кафедрой. Срок обучения по этой специальности составлял 5 лет (по специальности «Агрономия» срок обучения составлял 4 года 7 месяцев). В сравнении со специальностью «Агрономия» в учебный план новой специальности были включены новые дисциплины: цитология, общая селекция и сортоведение, иммунитет растений и селекция на устойчивость к болезням и вредителям, биотехнология с основами генной инженерии, частная селекция, семеноводство. Объем курса генетики увеличен в сравнение с программой по агрономии с 60 аудиторных часов до 160, и дисциплина получила название генетика (общая, популяций, количественных признаков и генетико-статистические методы в селекции). В рамках новой специальности предусматривались три специализации: «Селекция полевых и технических культур», «Селекция плодовых и овощных культур», «Биотехнология в селекции растений». На дисциплины специализаций отводилось 140 аудиторных часов. В целом же объем подготовки селекционера составлял 760 аудиторных часов. При условном переводе в современные единицы измерения это составляет 42 зачетные единицы. В учебном процессе давалось возможно полное представление о технологии селекционного и семеноводческого процессов. Уделялось внимание типичным ошибкам в работе селекционера и семеновода и «узким местам» технологии. Подготовка по данной специальности была бы неполной, если бы не дополнялась научно-исследовательской работой, связанной с селекционным процессом и практикой, в ходе которой организуются занятия по овладению селекционной техникой и экскурсии в селекционные и генетические учреждения.

Кроме того, после третьего курса была предусмотрена опытно-селекционная практика в объеме около двенадцати недель в период практически всей вегетации растений.

Переход на многоуровневую систему подготовки агрономов существенно сократил возможности подготовки селекционеров при их обу- чении в бакалавриате. Несмотря на созданный профиль подготовки «Селекция и генетика с.- х. растений», ряду специальных дисциплин не нашлось места в программе подготовки. Существенно, на один полевой сезон, сократилась практика студентов [4].

При переходе на новые образовательные стандарты, именуемые ФГОС 3++, в рамках существующих возможностей кафедрой генетики, биотехнологии и семеноводства совместно с деканатом факультета агрономии и биотехнологии РГАУ-МСХА имени К.А. Тимирязева удалось приблизить учебный план подготовки агрономов с профессиональным блоком «Селекция и генетика с.- х. культур» к учебному плану одноименной специальности, существовавшей до перехода на многоуровневую подготовку. Объем этого блока составил 37 зачетных единиц (против 42 в учебном плане специальности) и включает дисциплины: общая селекция, биологические основы селекции и семеноводства, цитология, генетика популяций и количественных признаков, основы молекулярной биологии, основы генной инженерии, иммунитет растений и селекция на устойчивость, селекция полевых культур, семеноводство и семеноведение, статистические методы в генетике. Для всех, обучающихся по направлению «Агрономия», в учебном плане предусмотрены технологическая практика и научно-исследовательская работа общим объемом двенадцать недель, а также четыре недели преддипломной практики. Использовать практику продуктивно можно только при совместной с научными учреждениями и селекционными центрами разработке программ. В то же время необходимо отметить, что времени на практическую подготовку специалиста по селекции явно недостаточно.

Кафедра генетики, селекции и семеноводства РГАУ-МСХА имени К.А.Тимирязева и сегодня является базовой по преподаванию дисциплин селекции и семеноводства в России и странах СНГ. Сотрудники кафедры регулярно поднимают вопрос о качественной подготовке селекционеров и семеноводов [1, 2]. Кафедра была и остается методическим центром подготовки селекционеров. Подготовленные ее сотрудниками учебники были основными для всех вузов страны. Только в последние годы (за период 20132019 годы) преподавателями кафедры подготовлены и изданы учебники «Общая селекция», «Частная селек- 
ция полевых культур», «Практикум по селекции и семеноводству полевых культур», «Селекция полевых культур на качество», учебное пособие «Рабочая тетрадь по семеноводству» и ряд других [3, 4, 5, 6].

Раз в три-четыре года коллектив кафедры проводит семинары по методическим вопросам преподавания данных дисциплин в с. - х. вузах.

В течение двенадцати лет на базе кафедры проводятся 72 часовые курсы повышения квалификации «Основы сертификации семян с. - х. растений и ее структурные элементы». Курсы предназначены для работников Россельхозцентра, Россельхознадзора, частных компаний, специалистов-семеноводов. Они проходят два раза в год по 25-28 человек в один поток. Преподаватели кафедры участвуют также в проведении курсов подготовки агрономовапробаторов (раз в год).

Опыт работы кафедры генетики, селекции и семеноводства РГАУ-МСХА имени К.А.Тимирязева и ряда кафедр ведущих с.- х. вузов страны показывает, что необходимо существенно усилить подготовку и увеличить выпуск селекционеров. Исходя из этого, целесообразно сконцентрировать подготовку селекционеров в нескольких с.- х. вузах страны. На наш взгляд, это РГАУ-МСХА, Воронежский, Омский, Новосибирский, Саратовский ГАУ.

Для высококачественной подготовки селекционеров требуется также укрепление материально-технической базы профильных кафедр и связанных с ними структурных подразделений современной селекционно-семеноводческой техникой и лабораторным оборудованием.

Новый возможный подъем, связанный с подготовкой селекционеров, может опираться в первую очередь на Федеральную научно-техническую программу развития сельского хозяйства на 2017-2025 годы [7]. При реализации этой программы будет решено множество важнейших задач. Мы остановимся на тех, которые связаны с подготовкой будущих селекционеров: создание и внедрение технологий производства семян высших категорий (оригинальных и элитных) c.- х. растений, племенной продукции (материала) по направлениям отечественного растениеводства и животноводства, имеющим в настоящее время высокую степень зависимости от семян или племенной продукции (материала) зарубежного производства; совершенствование системы подго- товки дополнительного профессионального образования кадров для агропромышленного комплекса, ориентированной на быструю адаптацию к требованиям научно-технического прогресса.

Ожидаемый результат реализации Программы - доведение до $100 \%$ уровня обеспеченности системы профессионального образования образовательными программами по новым направлениям подготовки и специальностям, созданным по направлениям реализации Программы.

Непосредственно с Программой связано несколько Федеральных научно-технических программ (ФНТП), в том числе:

- развитие селекции и семеноводства картофеля;

- развитие селекции и семеноводства сахарной свеклы;

- развитие селекции и семеноводства масличных культур;

- развитие селекции и семеноводства кукурузы;

- развитие селекции и семеноводства технических культур;

- развитие селекции и семеноводства овощных культур;

- развитие селекции и переработки зерновых культур.

Область профессиональной деятельности выпускников, освоивших программу бакалавриата (35.03.04 «Агрономия»), включает: (в сфере производства и хранения продукции растениеводства на основе достижений агрономии, защиты растений, генетики, селекции, семеноводства и биотехнологии с.х. культур). Выпускник должен обладать следующими профессиональными компетенциями:

- организовывать испытания селекционных достижений;

- организовывать выведение новых сортов и гибридов с. - х. культур;

- организовывать разработку технологий получения высококачественных семян с. - х. культур;

- осуществлять сортовой и семенной контроль.

При разработке будущей направленности или направления «Селекция» могут возникнуть следующие сложности:

- разработка образовательной программы с типом задач профессиональной деятельности выпускника в области селекции в рамках направления 35.03.04 «Агрономия»;

- формирование базовых теоретических знаний в области селекции в рамках предложенных примерных образовательных программ направ- ления 35.03.04 «Агрономия»;

- качественная реализация образовательной программы в области селекции в группе численностью до 30 человек [8];

- невозможность (ввиду запроса реального сектора АПК) снижения контингента обучающихся на направлении «Агрономия» (направленности «Агрономия») за счет направленности «Селекция».

Сегодня в некоторых вузах реализуется в образовательном процессе профиль «Селекция и генетика с.х. растений» направления 35.03.04 «Агрономия» (РГАУ-МСХА имени К.А. Тимирязева, Саратовский ГАУ имени Н.И. Вавилова, Воронежский ГАУ имени императора Петра I, Новосибирский ГАУ, Омский ГАУ имени П.А. Столыпина, Оренбургский ГАУ).

Как повлияли мероприятия, связанные с переходом на многоступенчатую систему образования, на состояние коллективов - кафедр в ВУЗах, их наличие, или отсутствие, a, соответственно и на безопасность страны? В какой-то степени об этом можно судить по цифрам, приведенным в таблице.

Если проанализировать цифры этой таблицы, то можно сделать предварительный вывод. Около половины вузов, по причине оптимизации количества кафедр, а, следовательно, и, состава преподавателей, по всей видимости, в результате этих мероприятий выполняют свои функции по многим дисциплинам и предметам чисто формально. Вузов, которые сохранили такие кафедры, как селекция и семеноводство и защита растений, как в составе соединенных кафедр, так и в составе пока отдельных кафедр, насчитывается около трети. Выводы читатели могут сделать сами.

И еще один аспект. Традиционная статистика конкурса абитуриентов c. - х. вузов (чел/место) сегодня не может адекватно отражать ситуацию вследствие действующего положения о возможности подачи абитуриентами документов с результатами ЕГЭ сразу в несколько высших учебных заведений.

Как повлияет сложившаяся в образовательном процессе ситуация на выполнение Федеральных научно-технических программ, семь из которых связаны с селекцией и семеноводством?

В Российской Федерации селекционные достижения, сорта и гибриды растений, создаются селекционе- 


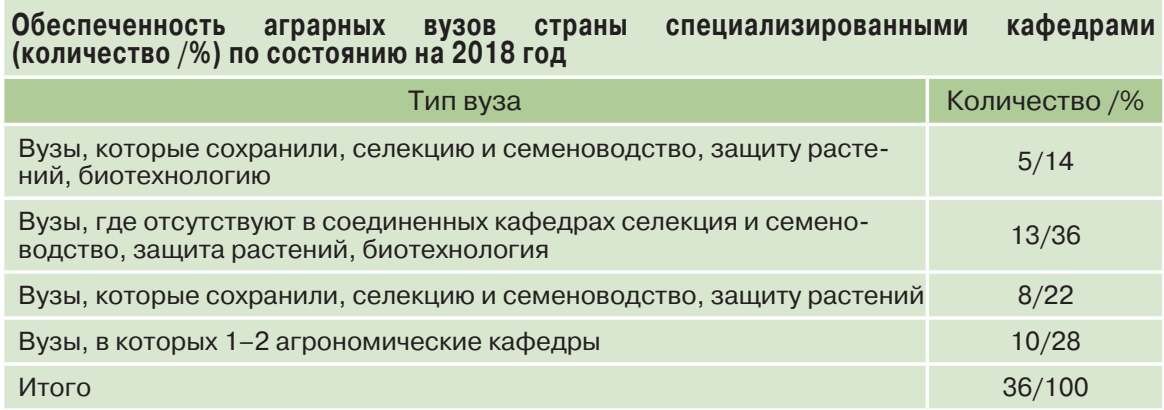

рами, которые работают в государственных и частных организациях, или являются физическими лицами [11].

Как уже отмечалось нами ранее, достижения селекционеров используются в товарном производстве и нетоварном (личном подсобном), последнее особенно востребовано для картофелеводства и овощеводства. Серьезную конкуренцию по результатам нашей селекции в целом составляют иностранные организации, как национальные селекционно-семеноводческие фирмы, так и транснациональные корпорации со своими сортами и гибридами, а последние - и со своими пестицидами, созданными непосредственно под конкретные гибриды. Только по достижениям в области селекции зерновых культур мы можем чувствовать себя относительно защищенными. По остальным культурам зависимость от иностранных семян (речь идет не о репродукции отечественных оригинальных семян за границей) составляет: по сахарной свекле 99\%, овощным культурам - 70\%, подсолнечнику и картофелю - 60\%, кукурузе - 50\%, льну - долгунцу - 20\%.

Так как в нашей стране значительная часть селекционных достижений создается в государственных учреждениях, то и выполнение данных программ связано также с ними. Обеспеченность НИИ оборудованием часто находится на уровне конца восьмидесятых годов прошлого века. Селекционеры, работающие в государственных учреждениях, как правило, предпенсионного и пенсионного возраста. Аспирантура в НИИ некоторое время отсутствовала, и, возможно, возродится в Федеральных центрах. Обеспеченность жильем и заработной платой также может удовлетворять только пожилых сотрудников.

Существуют частные отечественные селекционно-семеноводческие компании, причем некоторые из них пытаются достаточно успешно конкурировать с иностранными фирмами, в том числе и на рынке профессиональных семян. Если в области оборудования, необходимого для ведения селекционного процесса, и оплаты труда селекционеров отечественные компании вкладывают значительные финансовые средства, то на подготовку селекционеров они могут оказывать весьма незначительное влияние, а на учебный процесс - никакого.

\section{Заключение}

Таким образом, учитывая направления и пути развития селекционной и семеноводческой работы в растениеводстве, возникает необходимость подготовки узкопрофильных специалистов, которые смогут на современном уровне решать задачи импортозамещения и повышения независимости российского сельского хозяйства от поставок зарубежного посевного материала. Нормативные правовые документы в области высшего образования позволяют формировать более гибкие образовательные программы в магистратуре.

В частности, выпускник бакалавриата по направлению 35.03.04 «Агрономия» в течение двух лет может специализироваться в области селекции и семеноводства в магистратуре по этому же направлению, овладевая необходимыми компетенциями. В соответствии с ФГОС ВО3++ по направлению 35.04.04 «Агрономия» профессиональные компетенции формируются образовательными организациями на основе профессиональных стандартов (при наличии), с учетом требований работодателей и с учетом примерных основных образовательных программ (ПООП). В настоящее время разработан и размещен в интернете на сайте «пооп.рф» проект ПООП по указанному выше направлению уровня подготовки магистратура.

Однако профессиональные компетенции, рекомендуемые ПООП, не в полной мере отражают специфику подготовки специалиста в области селекции и семеноводства. Соответственно и примерный учебный план не содержит необходимых обязательных дисциплин, направленных на формирование общепро- фессиональных и профессиональных компетенций будущих селекционеров-семеноводов.

Практика показывает, что в рамках одного направления могут быть сформированы две и более ПООП для обеспечения различных отраслей квалифицированными специалистами. В связи с этим необходимо в ближайшее время разработать ПООП по профилю селекция и семеноводство с.- х. культур в рамках направления 35.04.04 «Агрономия». Целесообразно привлечь к этой работе специалистов научно-исследовательских институтов, селекционных центров, с. - х. организаций, осуществляющих семеноводство.

\section{Библиографический список}

1.Создание и реализация учебно-методического обеспечения курсов повышения квалификации по сертификации сельскохозяйственных растений и ее структурные элементы / А.М. Малько, А.Н. Березкин, В.В. Пыльнев, В.С. Рубец, А.М. Бакштанин // Трудь Кубанского государственного аграрного университета, 2017. Вып. 3 (66). С. 164-168.

2.Пыльнев В.В. О подготовке кадров селекционеров и семеноводов в Российском аграрном университете имени К.А.Тимирязева // Состояние и перспективы развития семеноводства в Российской Федерации в современных условиях: мат.межд. научно-практ. конф. Курган, 2019. С. 44-48.

3.Общая селекция растений / Ю.Б. Коновалов, В.В. Пыльнев, Т.И. Хупацария, В.С. Рубец СПб.: Лань, 2018. $480 \mathrm{c}$

4.Пыльнев В.В., Коновалов Ю.Б., Березкин А.Н и др. Практикум по селекции и семеноводству полевых культур. СПб. М.: Лань, 2014. 448 с.

5.Пыльнев В.В., Коновалов Ю.Б., Буко О.А. и др. Частная селекция полевых культур //. СПб. М.: Лань, 2016. 544 c.

6.Рабочая тетрадь для лабораторно-практических занятий по курсу «Семеноводство» / А.М. Малько, А.Н. Березкин, В.В. Пыльнев, В.С. Рубец, О.А. Буко СПб.М.: Лань, 2019. 200 с.

7.Федеральная научно-техническая программа развития сельского хозяйства на 2017-2025 годы.

8.Приказ Министерства образования и науки Российской Федерации от 05.04.2017 г. № 301 «Об утверждении Порядка организации и осуществления образовательной деятельности по образовательным программам высшего образования - программам бакалавриата, программам специалитета, программам магистратуры». [Электронный ресурс]. URL: https:// rg.ru/2017/07/19/minobr-prikaz301-site-dok.html. Дата обращения: 3.09.2019.

9.Новости «Агрообразование» [Электронный pecypc]. URL: http://agroob.ru/index.php/ novosti/176-v-bryanskom-gosudarstvennomagrarnom-universitete-29-30-maya-2019-godasostoyalsya-vserossijskij-seminar-soveshchaniedekanov-agronomicheskikh-fakultetov-vuzovminselkhoza-rossii-i-minobrnauki-rossii-na-temusovershenstvovanie-podgotovki-agronomicheskikh. Дата обращения: 3.09.2019.

10.Федеральный закон от 24 октября 2007 г. N 232 Ф3 «О внесении изменений в отдельные законодательные акты Российской Федерации (в части установления уровней высшего профессионального образования)» [Электронный ресурс]. URL: https://legalacts. ru/doc/federalnyi-zakon-ot-24102007-n-232-fz-o/. Дата обращения: 3.09.2019.

11.Государственный реестр селекционных достижений допущенных к использованию. Том 1. Сорта растений [Электронный ресурс]. URL: https://reestr.gossort. com/. Дата обращения: 3.09.2019. 


\section{Об авторах}

Бердышев Виктор Егорович, доктор техн. наук, профессор, председатель Федерального учебно-методического объединения в системе высшего образования по укрупненной группе специальностей и направлений подготовки 35.00.00 Сельское, лесное и рыбное хозяйство.

E-mail: educ@mail.ru

\section{Клименко Николай Николаевич,} канд. с. - х. наук, доцент, директор Агрохолдинга «Поиск».

E-mail: n.klimenko@poiskseeds.ru

Леунов Владимир Иванович, доктор с. - х. наук, профессор, и.о. декана факультета агрономии и биотехнолоГИи, ФГБОУ ВО РГАУ - МСХА Имени К.А. Тимирязева.

E-mail:vileunov@mail.ru

\section{Пыльнев Владимир}

Валентинович, доктор биол. наук, профессор, и.о. зав. кафедрой генетики, селекции и семеноводства, ФГБОУ ВО РГАУ - МСХА им. К.А. Тимирязева.E-mail: pyl8@yandex.ru

Education of breeders in institutes of higher education and implementation of state breeding programs in Russia V.E. Berdyshev, DSc, professor, head of the Federal educational and methodical Association in the system of higher education in the enlarged group of specialties and areas of training 35.00.00 Agriculture, forestry and fisheries. E-mail:educ@mail.ru

N.N. Klimenko, PhD, associate professor, director of Poisk Agro Holding.

E-mail: n.klimenko@poiskseeds.ru

V.I. Leunov, DSc, professor, acting dean of faculty of agronomy and biotechnology, Russian State Agrarian University - Moscow Timiryazev Agricultural Academy.

E-mail: vileunov@mail.ru

V.V. Pyl'nev, DSc, acting head of department of genetics, breeding and seed growing, Russian State Agrarian University Moscow Timiryazev Agricultural Academy. E-mail:pyl8@yandex.ru

Summary. Brief information about training scientists and breeders abroad is presented, as well as detailed information about the education system for breeders in Russian Federation. The basic problems of national education in the field of breeding of agricultural crops in connection with state breeding programs are touched upon.

Keywords: training, selection, seed production. 